\title{
Estudiar historia para descubrir al chino de la familia'
}

Recibido: 19/02/2020

Aprobado: 20/05/2020

Carlota Casalino Sen

Publicado: $25 / 08 / 2020$

Universidad Nacional Mayor de San Marcos <ccasalinos@unmsm.edu.pe>

\section{RESUMEN}

El presente trabajo es un ejercicio de memoria organizada en torno a dos aspectos. El primero relacionado a la rememoración sobre el bisabuelo que llegó al sur del Perú desde la China. El segundo, sobre mi contacto con la cultura chino-peruana durante mi infancia y adolescencia. Destaco dicha impronta marcada desde lo cotidiano, por lo que suele ser imperceptible y subjetiva.

Palabras clave: Perú; Chinos; Tusán; Memoria; Vida cotidiana

\section{Study history to discover the chinese of the family}

\section{ABSTRACT}

This essay is a memory exercise around two aspects. The first is related to the remembrance of the great - grandfather who arrived in from China to southern Peru. The second, about my experience with the chinese - peruvian culture during my childhood and adolescence. During this exercise, I highlight a personal imprint from the everyday, so it is usually imperceptible and subjective.

KeY words: Peru; Chinese; Tusan; Memory; Everyday experience 


\section{Introducción}

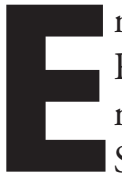
n primer lugar, deseo agradecer a Humberto Rodríguez Pastor por organizar esta mesa redonda sobre «Tusanes y Nikkeis Sanmarquinos», y por invitarme a participar en ella, así como a la Facultad por patrocinar tan excelente iniciativa.

Hace muchos ańos, conversando con Humberto, me preguntó por mi condición de tusán. Esa conversación hizo que me diera cuenta de que una de las razones por las cuales estudié historia fue justamente por eso, porque quería saber cómo así tenía un apellido chino, si mi mamá era de Subtanjalla — un pequeño pueblito en la entrada de Ica- - y mi papá era de más al sur, Acarí, Arequipa, ¿¿de dónde entonces el apellido chino de mi mamá?

Entonces, esta oportunidad de conversar entre sanmarquinos me permitirá recordar y organizar mis recuerdos, memorias e información que he ido acumulando a lo largo de los años. Por eso, y tal como propuso el organizador, empezaré relatando sobre mi antepasado chino, luego lo que recuerdo sobre la comunidad tusán, después cómo se expresó la cultura chino-criolla en mi vida cotidiana — niñez y adolescencia-, para culminar con la herencia o legado de esa cultura en mi vida personal.

He optado por el relato, como estilo de escritura, porque necesariamente me voy a remitir a recuerdos, no solo míos, sino a los recuerdos de mi madre, quien, siendo reacia a contar cualquier cosa de su vida, tuvo que ceder a mis incesantes preguntas durante mi adolescencia. Por lo tanto, son recuerdos de recuerdos y agradeceré que los tomen como tales. No obstante, en algunos puntos y reflexiones me he atrevido a insertar algunos autores para ayudarme en el orden y comprensión de las experiencias.

\section{Mi ancestro chino}

Hace muchísimos años mi mamá me contó que mi bisabuelo llegó al Perú, y que fue contratado por la hacienda de los Picasso en Ica. Probablemente llegó a través del puerto de Pisco, como miles de chinos que Domingo Elías trajera desde mediados del siglo XIX. Es del caso señalar que los Picasso también fueron inmigrantes —italianos- que llegaron al Perú en 1850 y se establecieron en Ica, tuvieron a su cargo varias haciendas —entre ellas Vista Alegre-y se dedicaron a la producción de vino, de algodón y caña. (Martínez 2017: 59). Deduzco que el bisabuelo llegó después de la Guerra con Chile, porque su mujer -Eudocia - tenía entre once y trece años cuando la guerra y tuvo que treparse a un árbol para salvar su vida cuando los chilenos pasaron y repasaron por esa zona. Así, cuando mi bisabuela conoció mi bisabuelo ya era una persona con más edad. Esto empata bien con la manera como ellos vivieron, pues a diferencia del cultivo de vid y de caña, por las características del algodón, el trabajo se hacía con arrendatarios, es decir los trabajadores para que se queden más allá del tiempo del recojo del algodón, tuvieron acceso a tierras de la hacienda para trabajarlas para ellos (Thorp y Bertram 1978: 73-75), así es como Eudocia, hija de arrendatarios de los Picasso conoció al bisabuelo. Sin embargo, no hay certeza de ello, el bisabuelo pudo haber llegado con el último barco que trajo a los culíes en 1874 y sobrevivió a la guerra, o llegó después de esta pero no en grupos masivos sino como inmigrante voluntario. Para Rodríguez Pastor, al parecer también hubo una modalidad de yanaconaje moderno en el cual, los chinos recibían una porción de tierra para cultivar. Sin embargo, en el caso del bisabuelo no se conoce si también él tuvo acceso a esa tierra, o en caso contrario, fue un semiasalariado (Rodríguez Pastor 2000: 42).

$\mathrm{Su}$ nombre fue Sen Li Un, pero nadie recuerda de qué parte de China provino. Él se encargaba de manejar las máquinas que ayudaban a sacar las pepas del algodón. Es decir, en un principio trabajaba con la desmotadora. Tal como seńala Rodríguez Pastor, las haciendas introdujeron maquinaria moderna a vapor que permitía el desmote del algodón (Rodríguez Pastor 2000: 39).

Lo que se recuerda de su vida cotidiana es que solía cocinar, nunca quiso enseñar a nadie hablar chino, incluso parece que en algún momento perdió el nombre por el del contratista que lo llevó a Ica. Pero esa última parte de la historia no está muy clara. Esta es la única información que logré obtener hace muchísimos años y después de varias preguntas respecto a mi antepasado. Pero, esos datos tan escasos me generaron mucha curiosidad, y nadie en casa, ni mis tías en Ica, me sabían responder, por eso cuando decidí estudiar en la universidad, entre todas las carreras que me 
interesaban en esa época (arqueología, antropología, trabajo social e historia) decidí por esta última. Entre otras razones, para tratar de saber por qué había un chino en mi familia. De hecho, no encontré más información, pero sí estudié a los chinos como grupo social, me interesó saber qué tácticas de resistencia y microrresistencias utilizaron frente a una sociedad adversa a cualquier comunidad diferente, para poder pasar de ser un grupo de inmigrantes marginales y rechazado por la sociedad peruana, a ser un grupo reconocido socialmente en la actualidad (Casalino 2005: 110).

Hay un tema que me parece relevante y que mencioné en líneas previas y en el cual deseo detenerme un momento. Se trata del asunto de los patronímicos. Los chinos culíes sufrieron del cambio de sus nombres una vez arribaron en algún puerto peruano. $\mathrm{Al}$ respecto Rodríguez Pastor señala cómo se produjo la adopción, imposición o permanencia de los nombres de los trabajadores chinos, pues dependiendo la unidad productiva a la que se incorporaban, podían mantener o cambiarles sus nombres. (pp. 365-387) Pero, si bien tuvieron que aceptar dicha situación, no significaba ello que perdían su identidad, pues al momento de morir, retomaban sus nombres y recuperaban sus lugares de origen. Eso lo comprobé en Lima, cuando hice el trabajo de campo para mi tesis de maestría en el Cementerio Presbítero Matías Maestro, y encontré lápidas de chinos con nombres y apellidos occidentales, pero había ideogramas chinos pintados en color verde, o en bajo relieve pintados con tinta negra o en dorado, que incluía el apellido y nombre que iban al centro de la lápida, así como — la casa- el lugar y la fecha de nacimiento y de fallecimiento iban a la izquierda y derecha respectivamente. Desde 1840 ya se encuentran chinos enterrados en -el entonces- Cementerio General. Entre 1840 y 1860 la mayor causa de fallecimiento de chinos fue por fiebres y disentería. Las fiebres era el nombre común a la malaria. Varios de ellos provenían de las parroquias del Sagrario, Cercado y Santa Ana. Los que fueron víctimas de la fiebre amarilla murieron en el Lazareto que se habilitó para atender esa epidemia. La mayoría de los fallecidos eran jóvenes entre veinte y veinticinco ańos. Aquellos que eran mayores —alrededor de 40 años- solían ser enterrados en nichos, destacando los cuarteles Santa Rosa, San
Gavino, Vicente de Paula, Buen Pastor y San Camilo. (Casalino 1999: 113-123).

Entonces, en este acápite hemos visto cómo llegó el bisabuelo chino a la hacienda de los Picasso y casó con Eudocia una hija de inmigrantes - probablemente de Ayacucho- asentados en la misma hacienda en condición de arrendatarios o yanaconas. El bisabuelo fue uno de los miles de chinos que, tal vez obligado o por voluntad propia, asentó en estas tierras, organizó su vida y su descendencia.

\section{La comunidad tusán}

Respecto a mis recuerdos en torno a la comunidad tusán debo decir que esa experiencia se llevó a cabo en Lima en la década de 1970, pues mi madre migró un par de décadas previas a esta ciudad para trabajar cuando tenía más o menos quince años y ya tenía una hija, mi hermana mayor. No obstante, y a pesar de no tener más información sobre ese bisabuelo Sen, lo que recuerdo de la infancia y la adolescencia es que solía ir al barrio chino con bastante frecuencia, casi era un par de veces por semana. Una vez para ayudar con sus clases al hijo de la señora Brígida Chong que vivía en un edificio en la calle Paruro, pues que recuerde, ya trabajaba desde que tenía alrededor de 12 años. Otro día iba al barrio chino - generalmente sábados por las tardes - para acompañar a mi hermana mayor a la beneficencia china para que juegue ping pong. Ella tenía amigas y amigos con quienes se reunía, algunos además practicaban artes marciales y otros practicaban la danza del dragón, por lo que también solíamos ir para celebrar el año Nuevo Lunar. Lo que no sé es cómo así, ella participaba de esas actividades, no sé si la invitaron y cómo así tenía amigas y amigos tusanes. Aunque muchos años después casó con un nikkei, en la época que la acompañaba a Capón, ella tenía un enamorado tusán. Sin embargo, algo que recuerdo es que no era la mejor época del barrio chino, había grandes chifas y ya estaba la portada china, pero era un lugar en el que había que ir con cuidado. Después, cuando leí a Rodríguez Pastor (2017) recordé esas imágenes. Felizmente por ahí pasaba un ómnibus que tenía la ruta CocharcasJosé Leal y que tomábamos en la esquina de la casa y nos dejaba muy cerca de ahí. 
Entonces, algunos días de la semana, el barrio en mi caso era el chino, ahí donde por casualidad y sin querer desplegué prácticas culturales urbanas, donde se volvió un acto semicotidiano el circular por esos espacios apropiándolos, casi como si fueran espacios privados y no públicos a fuerza de repetición y coexistencia. Había, tal como sostienen De Certeau y Giard una práctica cultural, entendida como conjunto más o menos coherente, más o menos fluido, de elementos cotidianos concretos o ideológicos, a la vez dados por una tradición y puestos al día mediante comportamientos que traducen —en una visibilidad socialfragmentos de esa distribución cultural, de la misma manera que la enunciación traduce en el habla fragmentos de discurso (De Certeau y Giard 2006: 7-8).

Otro punto que valoro mucho fue que cuando más o menos tenía unos ocho años mis padres nos inscribieron - a cinco de los ocho hermanos - para que practiquemos Judo. Todos empezamos con entusiasmo, pero fue una disciplina que solo un hermano y yo seguimos con mayor persistencia. Por ejemplo, yo lo practiqué durante diez años en un dojo ubicado en el sótano del Colegio La Salle y el Sensei Bolaños fue mi maestro, mientras que mi hermano lo practicó en la YMCA. En realidad, querían que estudiáramos kung fu, pero decían que no había un buen lugar para practicarlo. Así, que poco a poco me dediqué a ello tres veces por semana, por lo que mi experiencia se abrió a otras culturas orientales criollas, pues en realidad muy pocos practicantes eran tusanes o nikkeis.

Fue en ese ambiente - por sugerencia de mi Sensei- que cayó en mis manos y leí el Tao Te Ching, y me interesó tanto que lo transcribí todo, y reflexionaba sobre cada pensamiento durante varios días. Me llamaron la atención tres capítulos en particular: el 2, 11 y el 26.

2.

Cuando las personas llegan a saber lo que es bello, aparece también la noción de lo feo.

Cuando llegan a saber lo que es bueno, aparece también la noción de lo malo.

De esta manera existencia e inexistencia, lo difícil y lo fácil, lo largo y lo corto, lo alto y lo bajo permiten conocer mutuamente lo uno y lo otro.

Los diferentes sonidos, uniéndose, crean la armonía. De la misma manera, lo anterior y lo siguiente van uno tras otro armoniosamente.
La persona sabia prefiere la no acción y permanece en el silencio. Todo pasa a su alrededor como por sí mismo. Ella no se siente apegada a nada en la Tierra. No se apropia de nada hecho por ella y después de crear algo, no se enorgullece de esto.

Puesto que esta persona no se ensalza, no alardea y no exige respeto especial de los demás, resulta agradable para todos.

11.

Treinta radios se unen en una rueda. Pero su utilización también depende del espacio vacío entre los radios.

Hacen los vasos de arcilla. Pero su utilización depende del espacio vacío que hay en estos.

Hacen paredes, puertas y ventanas en una casa. Pero su utilización también depende del espacio vacío que hay en esta.

Así es como se relaciona la utilidad de los objetos con el espacio vacío.

26.

El trabajo diligente permitirá alcanzar una existencia fácil en el futuro.

Pero también sabemos que la tranquilidad es lo más importante en el movimiento.

Por eso la persona sabia trabaja afanosamente todo el día sin dejar el trabajo duro. Con todo, haciéndolo, permanece en estado de perfecta tranquilidad.

Ella incluso puede vivir en el lujo y este no la corrompe.

¿Por qué, entonces, el dueño de mil carros de caballo, siendo orgulloso, desprecia el mundo entero? ¡El desprecio corroe el alma!

¡Y la ausencia de tranquilidad lleva a la pérdida del soporte!

Así fue como aprendí de la dialéctica oriental, de ver los dos lados de las cosas y de lo valioso que era mantenerse tranquilo, respirar y observar.

Para terminar este acápite, quiero referirme a un libro recientemente editado por Burga y Paredes titulado Hijos de inmigrantes. El estudiante sanmarquino de Historia (2019), ahí los autores — que son 24 estudiantes de Historia de San Marcos_ cuentan sus vidas, las de sus padres y de sus abuelos, respecto a diversos temas, entre ellos la migración y en qué generación se produjo la ruptura. Si aplico ese ejercicio a mi propia experiencia, puedo señalar que en $\mathrm{mi}$ caso hubo claramente tres rupturas, la de mi bisabue- 
lo chino que llegó hasta Ica, la de mi madre que salió de Subtanjalla y asentó en Lima, y la mía que salí de mi destino y entré a la universidad.

\section{La «cultura chino criolla»}

Algo que siempre estaba muy presente en la casa de la infancia y la adolescencia fue la comida, no solo porque era muy frecuente comer arroz con verduras salteadas, sino porque mi mamá, luego mis hermanas, y después cuando crecí y me tocó cocinar, teníamos que cocinar con lo que hubiere disponible. Siempre hacíamos un plato con lo que había. También era naturista, especialmente a partir de los ocho años que entré al Judo, pues prefería verduras y arroz, huevos y lácteos. Recién volví a comer carne, especialmente carne roja a los 19 años más o menos cuando ya estaba en San Marcos.

Entonces, en el caso de la cocina y la comida es bien importante la dimensión cotidiana. Se trata de aprender sutilmente los saberes cotidianos, que se aprenden no porque te "enseñan", sino porque se observa, se huele, toca, intuye... entonces sin querer aparecen los sabores, olores y colores... Ahí hay espacio para la invención y para tradición. Ahí se aprende adecuándose a las circunstancias, se aplica inteligencia y afectos a la vez. Por ello, me gusta la lectura de De Certau y Giard, porque justamente estudian la invención de lo cotidiano (De Certeau y Giard 2006: 153-154).

Otro aspecto particularmente interesante era que muy pocas veces nos enfermábamos, y cuando eso nos pasaba, mi mamá nos curaba con yerbas que traía del barrio chino. Generalmente eran infusiones que teníamos que tomar y que, según ella, nos mantenía sanos. Aprendí así, que el alimento puede ser una buena manera de prevenir enfermedades, que a veces nuestra mente nos traiciona y que tenemos que controlarla para no enfermar. Descubrí que los remedios occidentales son para casos de emergencia, cuando es inevitable, pero que después de transitar por la medicina occidental debo sanarme de aquello que me enfermó por curarme. Eso que hoy en día se conoce como recuperarse de los efectos secundarios de tomar medicinas, especialmente los antibióticos, que por ejemplo, te curan de una infección, pero que afectan al estómago, por ejemplo.

\section{Herencia sociocultural}

Antes de ingresar a San Marcos, ya era independiente, por lo que me organicé de tal manera que podía trabajar y estudiar a la vez. Según yo, en esa época dejé todas las costumbres y tradiciones familiares, como se dice "di una vuelta a la página». Sin embargo, conforme pasan los años, hay algunos saberes, prácticas y recorridos a los cuales he retornado, pero desde otra actitud, ya no obligada como era en mi niñez, sino porque me parece que bien vale la pena seguirlas. Por ejemplo, el asunto de la "comida", de los «remedios» como prevención para las enfermedades, el barrio chino que ahora es muy distinto al que conocí, el cementerio...

¿Cuál fue el legado? Una cultura oriental a la criolla en general y desde una perspectiva muy amplia. De manera implícita —entre prácticas y saberesaprendí un conjunto de actitudes que me permitieron destacar. Por ejemplo, el trabajo y la disciplina, el trazarme metas y orientar mis actos para cumplirlas. Hasta la paciencia y perseverancia, así como a pensar en la larga duración. Reconozco que esa fue la base sobre la cual aprendí a enfrentarme al mundo.

\section{Conclusiones}

Para finalizar, puedo señalar como conclusión que me puedo auto reconocer como tusán, al menos así lo expresé al representante del INEI en el último censo que se hizo en nuestro país. Lo hice en primer lugar, tomando en consideración el haber tenido un bisabuelo que inició esta historia y la base de la identidad. En segundo lugar, porque durante mi adolescencia culturalmente mi barrio de manera semi cotidiana fue Capón. En tercer lugar, porque entre mis interrelaciones y mis subjetividades hay algo de oriental muy persistente, a eso probablemente se deba a que, en San Marcos, mis amigos de la promoción y de la promoción anterior a la mía me llamaban «china» de cariño. 


\section{Fuentes y bibliografía consultada}

\section{Fuentes}

Lao Tsé (2008) [hace 2500 años], Tao Te Ching. Traducido al español por Antón Teplyy.

\section{Bibliografía}

Burga, M. y Paredes C. (2019). Hijos de inmigrantes. El estudiante sanmarquino de Historia. Lima: UNMSM.

Casalino, C. (1999). «La muerte en Lima en el siglo XIX: Una aproximación demográfica, política, social y cultural». Tesis para optar el grado de Magíster en Historia. Lima: PUCP.

Casalino, C. (2005). «De cómo los "chinos" se transformaron y nos transformaron en peruanos. La experiencia de los inmigrantes y su inserción en la sociedad peruana, 1849-1930». En: Investigaciones Sociales, Año IX, N. ${ }^{\circ} 15$, pp. 109-132.
Chunue, R. (2016). Capón. El barrio chino de Lima. Lima: Municipalidad de Lima.

De Certeau, M. (2007). La invención de lo cotidiano. 1. Artes de hacer. México: Universidad Iberoamericana.

De Certeau, M., Giard, L. y Mayol, P. (2006). La invención de lo cotidiano. 2. Habitar, cocinar. México: Universidad Iberoamericana.

Lausent, I. (2000). Sociedades y templos chinos en el Perú. Lima: Congreso del Perú.

Martínez, J. (2017). «Trabajo, poder y conflicto en San Jacinto, Valle de Nepeña-Áncash, 1860-2015». Informe de investigación 2016. Lima: Universidad Ricardo Palma.

Rodríguez, H. (2000). Herederos del dragón. Historia de la comunidad china en el Perú. Lima: Fondo Editorial del Congreso del Perú.

Rodríguez, H. (2017). Presencia, influencia y alcances. Chinos en la sociedad peruana. 1850-2000. Lima: UNMSM.

Thorp, R. y Bertram, G. (1978). Perú: 1890-977. Crecimiento y políticas en una economía abierta. Lima: Mosca azul editores - UP. 